\title{
CHARACTERIZATION OF COMPLEX PEBBLE MOVEMENT PATTERNS IN CHANNEL FLOW - A LABORATORY STUDY
}

\author{
K. BECKER, O. GRONZ*, S. WIRTZ, M. SEEGER, C. BRINGS, T. ISERLOH, \\ M.C. CASPER, J.B. RIES
}

Department of Physical Geography, Regional \& Environmental Sciences, Trier University, Germany.

\begin{abstract}
For a long time, studies concerning erosion caused by concentrated overland flow mainly dealt with the erosion and the transport of fine material. More recent studies have shown that rock fragments reduce the intensity of soil erosion processes on the one hand, but on the other hand rock fragment movements also have been observed both in the rill- and interrill erosion processes. However, there is little knowledge about the movement process of rock fragments in shallow channel flow. Are certain movement patterns typical for different shapes? Are there relationships between movement patterns and slope and flow velocity? Are all these patterns and relationships reproducible? To answer these questions, we performed laboratory channel experiments. With these experiments, we could obtain information about movement patterns of pebbles, by varying the following parameters: shape (flat, ellipsoidal, nearly spherical), size (diameter between 1.97 and $4.0 \mathrm{~cm}$ ) and channel slope $\left(5^{\circ}, 10^{\circ}\right)$. During the experiments, a high-speed camera was used to capture the motion of eight specially painted pebbles. The resulting image sequences were processed using both automatic image processing and manual visual inspection. Besides the movement patterns, the pebbles velocity, the water velocity and the water depth were estimated. We could show that there were different movement patterns depending on the shape and the slope. For the $5^{\circ} \mathrm{ex}$ periments, the big, flat pebbles lie at the beginning of the tests. After the following yawing, the pebbles mainly showed the movement form rolling around the longest axis. For the $10^{\circ}$ experiments the big, flat pebbles showed the same movement pattern firstly, but later in the sequence, they started to roll around their shortest axis and in the end this movement form was combined with saltation. These patterns are described using a simple symbolic language: sequences of pictograms describe the consecutive movement forms. Furthermore, we detected five different velocity groups of the pebbles for each slope: different cross-section shapes of the pebbles result in different acceleration behavior.
\end{abstract}

The methodology is limited to clear water in laboratory use. Even a larger water depth restricts the image processing. Thus, in the future the experiments will be combined with a small sensor that is implanted in the pebbles and measures forces (acceleration), compass (magnetic flux density) and rotations (gyroscope). 
Caracterización de patrones complejos de movimiento de gravas en flujos concentrados - Un estudio de laboratorio

RESUMEN. Durante mucho tiempo, las investigaciones sobre la erosión por flujos concentrados se centraban en la erosión y el transporte de materiales finos. Estudios más recientes han demostrado que, por un lado, los fragmentos de rocas pueden reducir la erosión, pero por otro, se han podido observar movimientos de éstos en pequeñas cárcavas o incluso en superficies sin concentración de la escorrentía superficial. Sin embargo, poco se conoce hasta ahora sobre los patrones de movimiento de los fragmentos de rocas dentro flujos efímeros concentrados. ¿Existen patrones de movimiento típicos para diferentes formas? ¿Existe una relación entre los diferentes patrones de movimiento y la pendiente y velocidad del flujo? Y, ¿son reproducibles esos patrones y esas relaciones? Para obtener información sobre los patrones de movimiento de gravas se realizaron experimentos en un canal de laboratorio variando los siguientes parámetros: forma (elipsoide, casi esférico, aplanado), tamaño (diámetros entre 1.97 y $4.0 \mathrm{~cm}$ ) de las gravas y pendiente $\left(5^{\circ}, 10^{\circ}\right)$ del canal. El movimiento de 8 piedras diferentes, pintadas especialmente para el caso, fue registrado con una cámara de alta velocidad. Las secuencias de imágenes resultantes fueron analizadas de forma automática al igual que de forma visual. Aparte de la identificación de los patrones de movimiento de las gravas se estimaron también la velocidad de éstas, así como la velocidad y la profundidad del agua. Se pudieron identificar diferentes patrones de movimiento dependiendo de la forma de la piedra y de la pendiente del canal. Al principio de los experimentos con pendiente de $5^{\circ}$, las gravas grandes y aplanadas que descansan sobre la superficie del canal, comienzan con un movimiento de guiñada para después pasar a rodar alrededor del eje mayor. Con una pendiente de $10^{\circ}$, estas mismas gravas comienzan el movimiento con el mismo patrón, para después pasar a rodar alrededor del eje más corto y finalmente combinar el rodamiento con saltos. Estos patrones se describen a base de un lenguaje simbólico simple: secuencias de pictogramas describen formas de movimiento consecutivas. Además, se identificaron 5 grupos de velocidad de las gravas para cada pendiente: cada sección transversal de la forma de la grava resulta en un patrón de aceleración diferente. La metodología está limitada a agua clara y el laboratorio. Mayores profundidades limitan las posibilidades de tratamiento de imágenes. Así, futuros experimentos se combinarán con un sensor instalado dentro de los fragmentos de roca que sea capaz de medir fuerzas (aceleración), orientación (densidad+ del campo magnético) y la rotación (giroscopio).

Key words: pebble movement forms, pebble movement patterns, cross-section shape, channel flow, laboratory channel study.

Palabras clave: movimiento de gravas, patrones de movimiento de gravas, forma de sección, escorrentía concentrada, estudio de canal de laboratorio.

Received 11 November 2014 Accepted 12 March 2015

*Corresponding author: Department of Physical Geography, Regional \& Environmental Sciences, Trier University, Germany. E-mail: gronz@uni-trier.de 


\section{Introduction}

Research on rock fragment movement by flowing water is an important issue in geomorphology. But the foci within this issue are very unevenly distributed. There are many studies on the influence of rock fragments on geomorphological processes (e.g. Poesen and Ingelmo-Sánchez, 1992; Bunte and Poesen, 1993a,b; Poesen et al., 1994; Rieke-Zapp et al., 2007) or on hydraulic conditions (Euler and Herget, 2012), if the rocks are stable on the ground, but there are less studies about moving rocks and especially on the movement patterns. And this is an important knowledge gap in this field of geomorphological research. Bed load transport, in general coarse rock fragments, is crucial for the development of channel beds (Rieke-Zapp et al., 2012; Wilson et al. 2013). But unfortunately, the bed load transport is quite difficult to describe or to quantify (Einstein, 1950). The results of some few studies indicate that rock fragment movement can reach very high values: Poesen (1987) estimated that maximum intensity of rock fragment (up to $9 \mathrm{~cm}$ in diameter) transport on a field plot by rill flow equals $256 \mathrm{~kg} \mathrm{~m}^{-1}$ $\mathrm{yr}^{-1}$.

In addition to the pure quantity of rock fragment movement, the type of movement of the rock fragments is crucial for their effect on the channel or riverbed, depending on movement range and the corresponding impact momentum (Sklar and Dietrich, 2001) respectively on the flux of impact kinetic energy (Sklar and Dietrich, 2004). Already in 1973, Francis described four modes of movement: sliding, rolling, saltating and suspension. In the sliding and rolling mode, the rock fragments do not lose ground contact; in the sliding mode, the axes orientations do not change; in the rolling mode, axes positions change. In the saltation mode, grains follow low, smooth trajectories. This movement pattern appears to be governed very largely by ballistic forces; in suspension, grains follow much longer, higher, wavy paths, which show up the influence of the irregular turbulence in the stream. Particle impact velocity and impact frequency depends on saltation trajectories (Sklar and Dietrich, 2004). In addition to the four movement patterns described by Francis (1973), Cameron (2012) added the moving form "vibrating". He states that before being picked up and moved by the flow, rocks tend to vibrate, and reach a characteristic "threshold" level of vibration before moving.

Another problem within the research on movement patterns is the fact that the above-mentioned single movement patterns are mostly combined and transitions between the movement patterns occur if environmental conditions change (Einstein, 1950). The transition from one mode to another is also readily observed within the study of Francis (1973). The grains spin in the three modes rolling, saltating and suspension. The trajectories of grains confirm that the change from saltation to suspension occurs near a stage when the vertical components of turbulent velocity are approximately equal to the settling velocity of grains.

All these studies show that it would be important to analyze rock fragment movement patterns and the transition between several patterns, but so far, the movement patterns of rocks have not been analyzed in sufficient detail (Cameron, 2012). For Ergenzinger and De Jong (2003), one main problem is the missing technique for field observations. Since 2003, new research methods have been developed but especially a detailed identification 
and description of the movement of rock fragments in flowing water; the complexity of movement patterns, depending on water flow conditions and on the morphology of the rock fragments, is still missing. In the present study we tackle the following questions:

1) Are certain movement patterns characteristic for certain pebble types?

2) Is there a characteristic transition between different movement patterns for a certain pebble type if slope and flow velocity change?

3) Are these patterns and the transitions reproducible?

Therefore, we analyzed movement patterns of differently sized and shaped pebbles in a laboratory flume using a high-speed camera. The discharge and the surface roughness of the bed were almost constant, but two different slopes have been used leading to different flow velocities.

\section{Materials and methods}

To answer these questions, a laboratory flume study has been conducted. Within this study, the movements of eight quartzite pebbles caused by tap water flow were observed. In the following subsections, the pebble selection and their particular properties, the experimental setup, the evaluation methodology and the symbolic language are described.

\subsection{Pebble selection}

The selection of pebbles was performed according to criteria in terms of material, size and shape: the relevant range of each property should be represented. After a preselection of a larger set of pebbles out of the medium and coarse gravel classes, eight pebbles were finally chosen based on the diameters $d_{a}$ (longest axis), $d_{b}$ (medium), $d_{c}$ (short), density and material (Table 1).

Table 1. Pebble properties. Used abbreviations: the shape can be flat (f), ellipsoidal (e) or almost spherical (as); the size can be small $(s)\left(d_{a}\right.$ between 2 and $\left.3 \mathrm{~cm}\right)$ or big $(b)\left(d_{a}\right.$ between 3 and $4 \mathrm{~cm}$ ).

\begin{tabular}{|c|c|c|c|c|c|c|c|c|}
\hline \multirow{2}{*}{ ID } & \multirow{2}{*}{ Form (abbr.) } & \multirow{2}{*}{ Material } & \multirow{2}{*}{$\begin{array}{c}\text { Density } \\
{\left[\mathrm{g} \mathrm{l}^{-1}\right]}\end{array}$} & \multicolumn{3}{|c|}{ Length $[\mathrm{cm}]$} & \multirow{2}{*}{$\begin{array}{l}\text { Axial } \\
\text { ratio } \\
d_{c} / d_{a}\end{array}$} & \multirow{2}{*}{$\begin{array}{c}\text { Axial } \\
\text { ratio } \\
\left(\mathbf{d}_{\mathrm{a}}-\mathbf{d}_{\mathrm{b}}\right) /\left(\mathbf{d}_{\mathrm{a}}-\mathbf{d}_{\mathrm{c}}\right)\end{array}$} \\
\hline & & & & $\mathrm{d}_{\mathrm{a}}$ & $\mathrm{d}_{\mathrm{b}}$ & $d_{c}$ & & \\
\hline $\begin{array}{l}24 \\
25\end{array}$ & $\begin{array}{l}\text { small, flat }(s f) \\
\text { small, ellipsoidal (se) }\end{array}$ & $\begin{array}{l}\text { quartzite } \\
\text { quartzite }\end{array}$ & $\begin{array}{l}1.75 \\
1.80\end{array}$ & $\begin{array}{l}2.21 \\
2.30\end{array}$ & $\begin{array}{l}1.97 \\
1.90\end{array}$ & $\begin{array}{l}1.24 \\
1.60\end{array}$ & $\begin{array}{l}0.56 \\
0.70\end{array}$ & $\begin{array}{l}0.25 \\
0.57\end{array}$ \\
\hline $\begin{array}{l}2 \\
3\end{array}$ & $\begin{array}{l}\text { small, flat (sf) } \\
\text { small, ellipsoidal (se) }\end{array}$ & $\begin{array}{l}\text { quartzite } \\
\text { quartzite }\end{array}$ & $\begin{array}{l}2.50 \\
2.17\end{array}$ & $\begin{array}{l}2.34 \\
2.65\end{array}$ & $\begin{array}{l}2.22 \\
2.10\end{array}$ & $\begin{array}{l}1.36 \\
1.75\end{array}$ & $\begin{array}{l}0.70 \\
0.66\end{array}$ & $\begin{array}{l}0.12 \\
0.61\end{array}$ \\
\hline $\begin{array}{l}7 \\
5\end{array}$ & $\begin{array}{l}\text { big, flat }(\boldsymbol{b} f) \\
\text { big, } \boldsymbol{e l l i p s o i d a l ~}(\boldsymbol{b e})\end{array}$ & $\begin{array}{l}\text { quartzite } \\
\text { quartzite }\end{array}$ & $\begin{array}{l}2.67 \\
2.59\end{array}$ & $\begin{array}{l}4.34 \\
4.02\end{array}$ & $\begin{array}{l}3.80 \\
2.93\end{array}$ & $\begin{array}{l}1.97 \\
2.70\end{array}$ & $\begin{array}{l}0.45 \\
0.67\end{array}$ & $\begin{array}{l}0.23 \\
0.83\end{array}$ \\
\hline $\begin{array}{l}8 \\
6\end{array}$ & $\begin{array}{l}\text { big, } f \text { lat }(\boldsymbol{b} f) \\
\text { big, almost spherical (bas) }\end{array}$ & $\begin{array}{l}\text { quartzite } \\
\text { quartz }\end{array}$ & $\begin{array}{l}2.45 \\
2.50\end{array}$ & $\begin{array}{l}4.51 \\
3.68\end{array}$ & $\begin{array}{l}4.00 \\
3.59\end{array}$ & $\begin{array}{l}2.20 \\
2.86\end{array}$ & $\begin{array}{l}0.49 \\
0.88\end{array}$ & $\begin{array}{l}0.22 \\
0.11\end{array}$ \\
\hline
\end{tabular}


Fig. 1 shows the pebbles chosen for the study. We wanted to observe the differences in movement caused by size and form of the pebbles. So we selected pebbles in four different sizes, two for each size. Each pair of pebbles $(25 \& 24,3 \& 2,5 \& 7,6 \& 8)$ has nearly the same diameter, but differences in the form: one pebble is more ellipsoidal respectively nearly spherical (pebble 6), one is flatter.
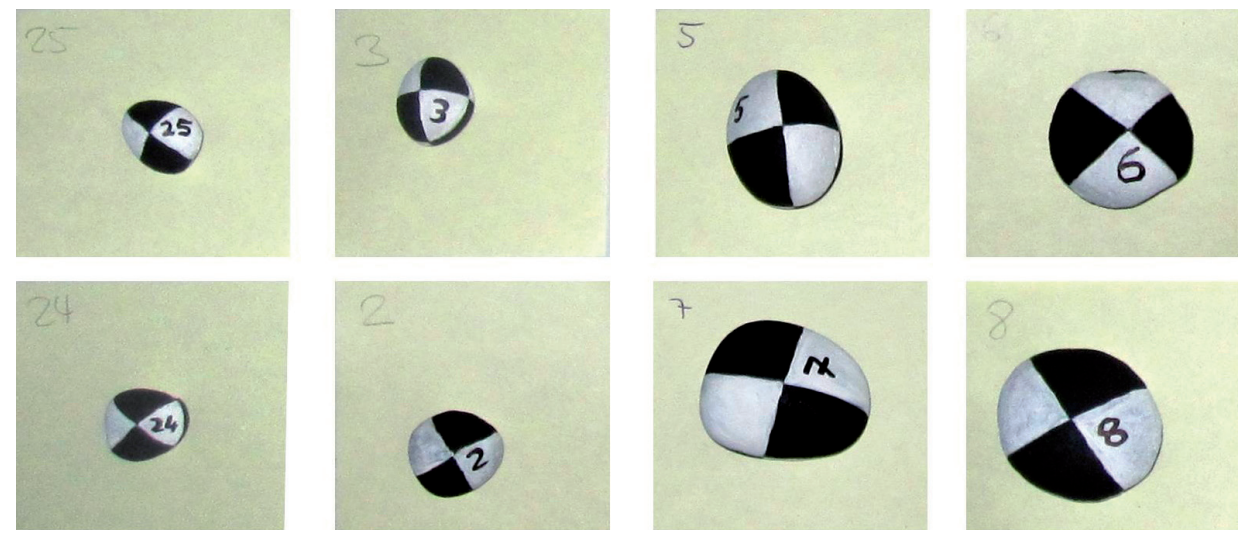

Figure 1. Selection of the pebbles. In the first row, the ellipsoidal pebbles $(25,3,5)$ as well as the nearly spherical one (6) are shown, in the second row the flat $(24,2,7,8)$ ones.

In this article, the abbreviations like shown in table 1 are used in addition to the pebble's id to highlight its specific characteristics. For example: Stone 3 is small and ellipsoidal, thus its abbreviation is 3 (se).

The pebbles were painted in black and white like the patterns used for crash test dummies (Fig. 2). Thus, the movement of the pebbles can be observed optically by a high-speed camera, which only produces greyscale images.

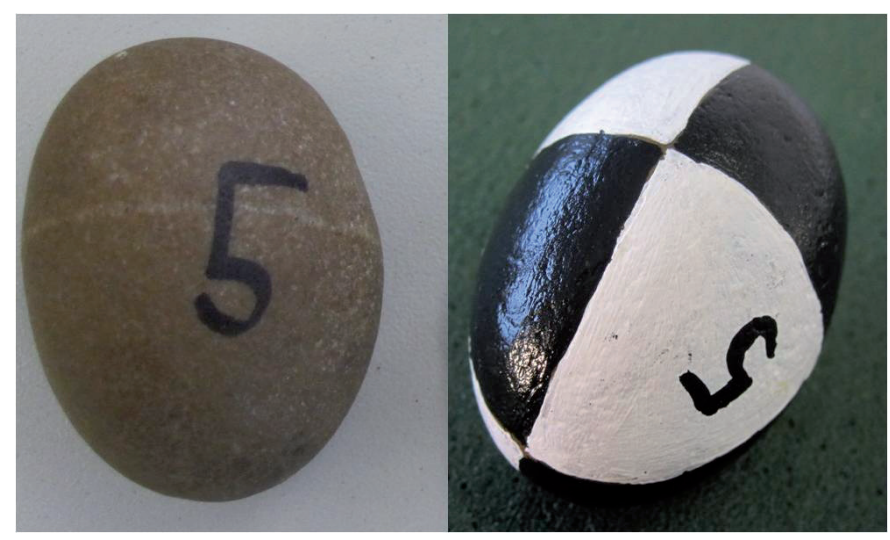

Figure 2. Pebble 5 before (left) and after the coloring. 


\subsection{The experimental setup}

The flume, shown in Fig. 3, is $270 \mathrm{~cm}$ in length and $26.5 \mathrm{~cm}$ in width. The flume bottom is covered with floral foam ( $210 \mathrm{~cm}$ long, $26.5 \mathrm{~cm}$ wide, $2.0 \mathrm{~cm}$ thick), which is fixed on a $0.5 \mathrm{~cm}$ thick aluminum sheet. Depending on the slope, the resulting flow depth is up to $2.0 \mathrm{~cm}$. The flume is made of acrylic glass. Its slope can be adjusted infinitely between $0^{\circ}$ and approx. $10^{\circ}$. An electrical effluent pump (Herborner Pumpenfabrik, type $0.75 / \mathrm{SH} 25$ ) with $0.75 \mathrm{hp}$ pumps the water in a water circulation system. The maximum discharge is $2751 \mathrm{~min}^{-1}$. The turbulence of the inflowing water is slightly reduced by plastic pipes of $10 \mathrm{~cm}$ length and a diameter of $1.3 \mathrm{~cm}$, arranged in a 20x8 stack. The pebble is positioned $35 \mathrm{~cm}$ downslope of the upper end of the floral foam to avoid the direct wave and turbulences of the inflowing water. Two different slopes $\left(5^{\circ}\right.$ and $\left.10^{\circ}\right)$ were chosen and the resulting flow velocities are described in table 2.

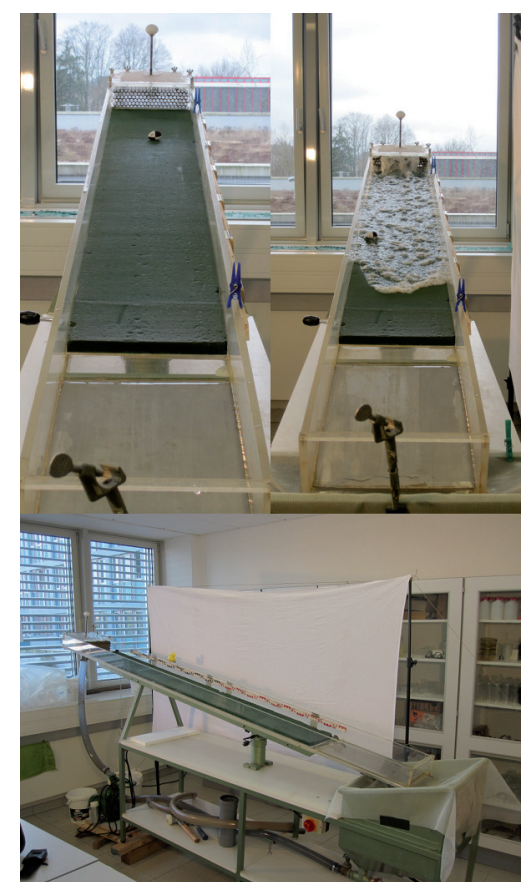

Figure 3. View of the experimental setup with a pebble in its initial position (upper left); during the experiment (upper right) and a total view of the flume (bottom).

Table 2. Flow velocity statistics for the two chosen slopes.

\begin{tabular}{|c|c|c|c|c|}
\hline $\begin{array}{c}\text { Slope } \\
{\left[{ }^{\circ}\right]}\end{array}$ & $\begin{array}{c}\text { Mean flow } \\
\text { velocity }\left[\mathrm{m} \mathrm{s}^{-1}\right]\end{array}$ & $\begin{array}{c}\text { Minimum flow } \\
\text { velocity }\left[\mathrm{m} \mathrm{s}^{-1}\right]\end{array}$ & $\begin{array}{c}\text { Maximum flow } \\
\text { velocity }\left[\mathrm{m} \mathrm{s}^{-1}\right]\end{array}$ & $\begin{array}{c}\text { Standard deviation of } \\
\text { flow velocity }\left[\mathbf{m ~ s}^{-1}\right]\end{array}$ \\
\hline 5 & 1.01 & 0.66 & 1.33 & 0.1 \\
\hline 10 & 1.37 & 0.99 & 1.99 & 0.21 \\
\hline
\end{tabular}


To capture the movements, we used an Optronis high speed camera (details in table 3). We used the software TimeBench of Optronis to control the high speed camera and to save the videos that were made to observe the movement of the pebbles during the tests. This software also converted the videos to a sequence of JPEG-image files.

Table 3. Technical data of the high speed camera used.

\begin{tabular}{|c|c|c|c|c|c|}
\hline Type & Lens & $\begin{array}{c}\text { Frames per } \\
\text { second [Fps] }\end{array}$ & $\begin{array}{c}\text { Resolution } \\
{[\text { [pixel] }}\end{array}$ & $\begin{array}{c}\text { Max. recording } \\
\text { time [s] }\end{array}$ & $\begin{array}{c}\text { Pixel size } \\
{[\mathbf{m m}]}\end{array}$ \\
\hline Optronis & $\begin{array}{c}\text { Tamron XR } \\
\text { DiIISp Af17 - } \\
50 \mathrm{~mm} \mathrm{1:2.8}\end{array}$ & $250\left(\right.$ for $10^{\circ}$ ) & $2304 \times 1720$ & 8 & 7 \\
\cline { 5 - 7 } CR4000 x 2 & $125{\text { (for } 5^{\circ} \text { ) }}^{5}$ & $2304 \times 1720$ & 12 & 7 \\
\hline
\end{tabular}

The high-speed camera has been positioned perpendicularly to the flume's center at a distance of about $3 \mathrm{~m}$ and oriented parallel to the flume slope. The resulting field of view covered the whole length of the flume. Thus, the camera did not have to move during the experiments. The resulting optical resolution in each image is $0.7 \mathrm{~mm}$ per pixel.

The scene has been illuminated by two halogen spotlights (direct illumination) and two LED spotlights (indirect) to ensure short exposure times of 4 and $8 \mathrm{~ms}$; the resulting image frequencies are 125 and 250 frames per second. In Fig. 4, a merged sequence of high speed image extracts is shown to illustrate the temporal resolution, the image quality, the sharpness resulting from short exposure times and the effect of the painting to support identifying movements.

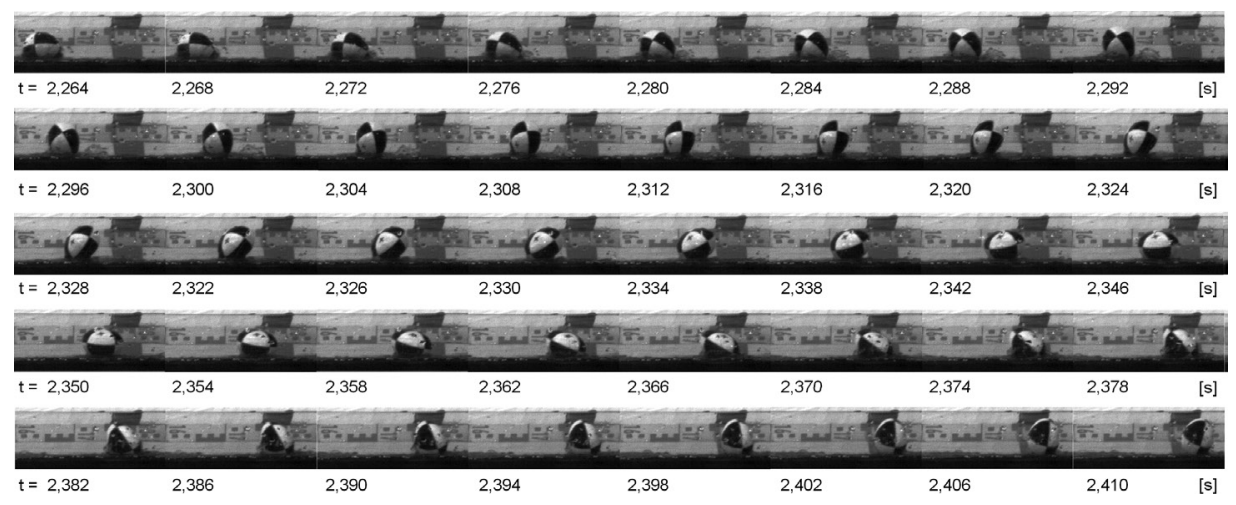

Figure 4. Merged high speed image sequence.

Each runs consists of the following steps: The pebble is positioned at the previously described position, the water pump and the high speed camera are started simultaneously, the pebble is transported by water to the flume lower end. Depending on the slope and the pebble size, the experiment lasts between 2.5 and 3 seconds. Each pebble has been captured with the given frame rates during 10 runs for each of the two different slopes. 
The number of runs per setting resulted from preliminary test, which showed that almost all pebbles moved in typical, recurring patterns. Asymmetrical stones were additionally placed in two different initial orientations (Fig. 5) to determine the influence of this orientation on the resulting movement pattern (again: 10 runs per orientation, pebble and slope). Thus, a total number of 220 runs has been conducted. Three of them were failures due to technical problems during image acquisition.

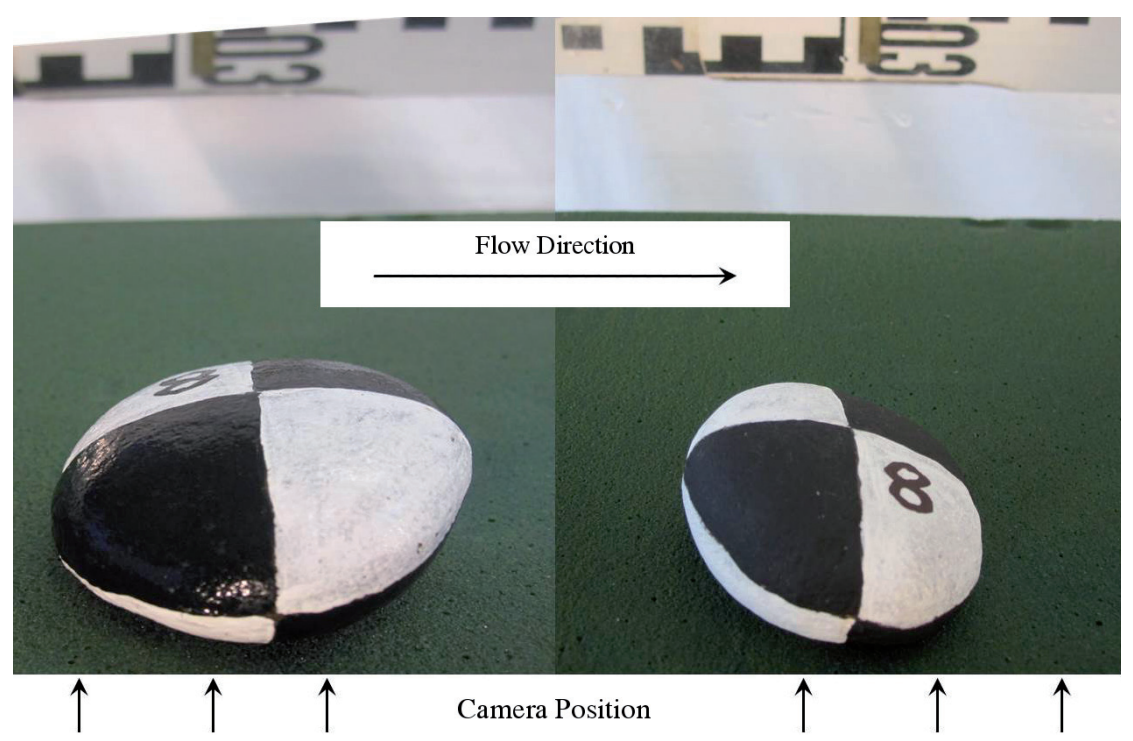

Figure 5. Illustration of the two different initial orientations: back left (BL) on the left hand and front right $(F R)$ on the right hand.

\subsection{Evaluation of image data}

In total, more than 200000 images have been acquired. To analyze this quantity, a combination of automatic, semi-automatic and computer-assisted evaluation techniques has been applied.

The water-level has been estimated automatically for each slope in a large set of images at the same position upstream of the pebble's initial position - including the beginning of each run, when the level is still rising - by application of the Canny edge detector (Canny, 1986). The level reached stable values after approx. 1 second for both slopes.

The flow velocity has been estimated at several places of the flume using particle image velocimetry. This method is useful especially for shallow flows, where conventional 
devices to measure flow velocities are not applicable (e.g. Meselhe et al., 2004). The results were already shown in table 2 .

Besides these two evaluations, which were mainly performed to validate the stability of the boundary conditions in each run, the derivation of the stone velocities from the image sequences was one main topic. For it, a MATLAB script has been implemented that shows the image sequence and facilitates the manual but still efficient marking of the stone's position in every 25 th frame by humans.

The actual movement patterns were determined manually. To describe the patterns and to allow for intuitive comparisons, a symbolic language has been introduced. This language consists of single symbols, each of which representing a specific movement (Table 4), following the basics in sediment transportation (Summerfield, 1991), the alignment of pebbles in rivers (Leser, 1977) and terms used in aviation (e.g. Steidle, 2009).

Table 4. Overview of the movement types, the representing symbol and a definition of the movement.

\begin{tabular}{c|l|l} 
Movement type & Symbol & Definition \\
\hline lie & $\begin{array}{l}\text { The pebble does not move despite the influence } \\
\text { of water. }\end{array}$ \\
\hline rotate & $\begin{array}{l}\text { The pebble is rotated clock-wise or anti- } \\
\text { clockwise. }\end{array}$ \\
\hline slide & $\begin{array}{l}\text { The pebble moves without changing the orien- } \\
\text { tation of the axes. }\end{array}$ \\
\hline roll around $d_{c}$ & The pebble rolls around the longest axis $d_{a}$. \\
\hline saltate & The pebble rolls around the shortest axis $d_{c}$. \\
\hline yaw & $\begin{array}{l}\text { The pebble looses ground contact for a short ti- } \\
\text { me. }\end{array}$ & $\begin{array}{l}\text { The pebble moves from left to right or from right } \\
\text { to left without changing position. }\end{array}$ \\
\hline pitch & The pebble moves up and down on the spot. \\
\hline s top view & &
\end{tabular}

As the movements can occur in combinations and furthermore vary in different runs of the same setting, additional symbols are introduced to describe sequences of (combined) movements. These symbols and their definition are described in table 5. They will be used later in the result section to describe the movement patterns. 
Table 5. Combination of different symbols to describe mixed movement forms or deviations in different runs.

\begin{tabular}{c|c|l} 
Variant & Characteristic & Definition \\
\hline 1 & $\begin{array}{l}\text { Movement is a mixed form of rolling around } d_{c} \\
\text { und saltation. }\end{array}$ \\
\hline 3 & $\begin{array}{l}\text { In } 2 \text { to } 4 \text { tests the pebble rolls around } d_{c} \text { and skips, } \\
\text { during the remaining test the pebble only rolls. }\end{array}$ \\
\hline 5 & $\begin{array}{l}\text { The bracketed pattern appears only in } 2 \text { to } 4 \text { tests; } \\
\text { during the remaining tests it does not occur. }\end{array}$ \\
\hline 5 & $\begin{array}{l}\text { Half of the tests show the pattern left to the slash, } \\
\text { the other half the pattern right to the slash. }\end{array}$ & $\begin{array}{l}\text { During half of the tests the pebble moves in a } \\
\text { mixing form of rolling around } d_{a} \text { and rotating. } \\
\text { During the other half it moves in a mixing form of } \\
\text { roll around } d_{c} \text { and rotating. }\end{array}$ \\
\hline
\end{tabular}

\section{Results and interpretation}

In total, 220 flume experiments have been conducted under laboratory conditions. Three runs had to be sorted out because of technical problems with the high-speed camera. The remaining 217 experiments resulted in more than 200000 images. The analysis of these images provides a good insight into pebble velocity and pebble movement patterns under single pebble conditions without interaction between several pebbles.

\subsection{Pebble velocities}

As mentioned in section 2.3, the pebble velocities were derived from each 25 th frame of all runs. Fig. 6a shows one example of the analysis for pebble $3(\mathrm{se})$ and $10^{\circ}$ slope. At the beginning, the velocity increases almost equally in all runs and then stabilizes on a plateau. The levels of the plateaus differ slightly. This is mainly caused by the fluctuations in the water velocity that are shown in table 2. But generally, the velocity can be described as: steep ascent, stable plateau.

In the same way, five typical velocity trends can be formulated and their general development is shown in Fig. 6b.

- Velocity trend 1 is characterized by a steep increase at the beginning and an approach to a certain value. Within the $5^{\circ}$ slope experiments, all small pebbles 
(except for pebble 24) and the large pebbles 5(be) and 6(bas) in both orientations follow this trend. All ellipsoidal, both big and small, pebbles, the almost spherical one and the small, flat pebble show velocity trend 1 . Within the $10^{\circ}$ slope experiments the pebbles 3(se), 5(be) and 7(bf) in orientation BL follow trend 1 . Based on the almost constant trend at the end, we conclude that the maximum possible velocity has been reached under the prevailing conditions.

- Velocity trend 2 is characterized by an almost linear velocity increase. Pebble $24(\mathrm{sf})$ in the $5^{\circ}$ slope experiments, pebble 6 (bas) in both orientations and pebble 8 (bf) in orientation $\mathrm{BL}$ in the $10^{\circ}$ slope experiments follow this trend. For the pebbles following this trend the maximum velocity has not been reached under the prevailing conditions. Because of the almost linear development of the pebble velocity, we concluded that in case of a longer laboratory channel the pebbles could have reached even higher velocities.

- Velocity trend 3 is similar to velocity trend 1 for the first seconds. Both are characterized by a steep increase at the beginning and stabilization on a certain level. But velocity trend 3 shows a second increase until the end of the experiment. This velocity trend was only observed in the $10^{\circ}$ slope experiments for all small pebbles (except for pebble 3 ). The maximum velocity has not been reached under the prevailing conditions (compare velocity trend 2).

- Velocity trend 4 is characterized by a fluctuation around $0 \mathrm{~m} \mathrm{~s}^{-1}$ at the beginning. After this period, a steep increase follows up to a velocity level similar to velocity trend 1 . This velocity trend could be observed within the $5^{\circ}$ slope experiments for the large, flat pebble 7(bf) in both orientations and pebble 8(bf) in both orientations. Because of the almost constant velocity trend at the end, we assumed that the maximum velocity has been reached under the prevailing conditions.

- Velocity trend 5 is similar to velocity trend 2 but on a much lower level. The increase is almost linear for the whole experiment. This velocity trend could be observed for the big, flat pebbles 7 (bf) and 8 (bf) both in orientation FR within the $10^{\circ}$ slope experiments. The maximum velocity has not been reached under the prevailing conditions (compare velocity trend 2 ).

The velocity of the pebbles clearly depends on the water velocity (Table 2) that differs for the two slopes. Additionally the velocity trend is mainly influenced by the question if the pebble is rolling or not, by the movement of the pebbles in general and by the change between different movement patterns within one experiment. The exact pebble movement patterns will be shown and analyzed in the following section.

Except for pebble 7(bf) and pebble 8(bf), both in orientation FR in the $10^{\circ}$ slope experiments, all pebbles roll in a certain manner for both slopes. The main parameter controlling the velocity trend is the cross-section shape: the shape as seen perpendicular to the rotation axis. 

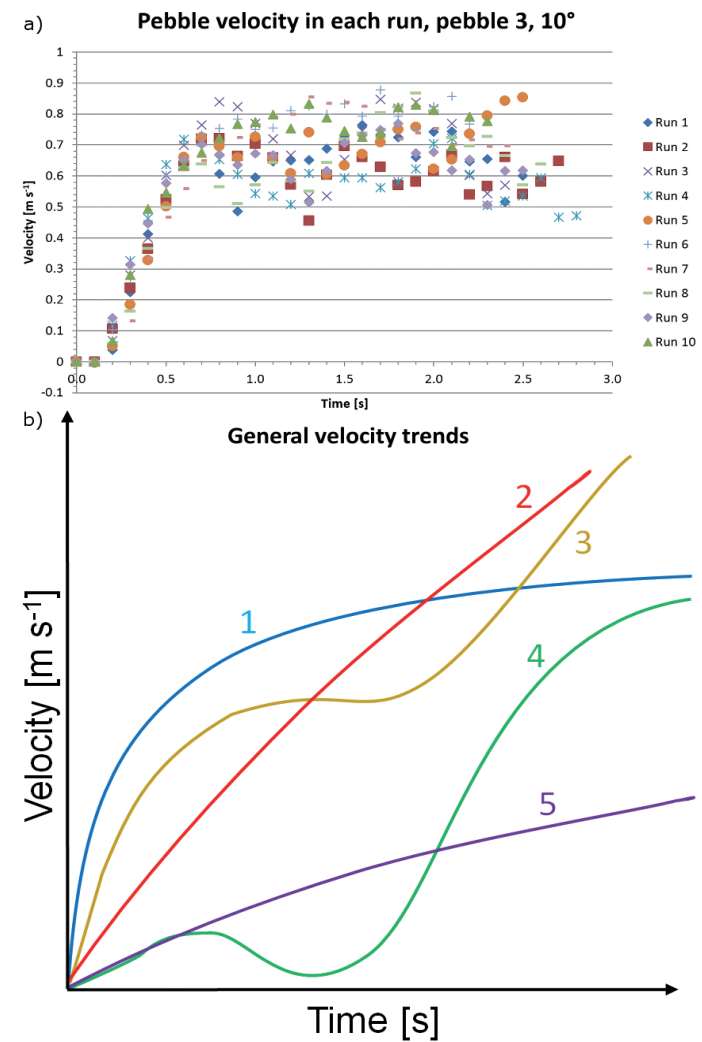

Figure 6. a) Example of detailed velocity data, pebble 3, $10^{\circ}$ and b) Derived typical velocity trends of all pebbles.

Within the $5^{\circ}$ slope experiments, the pebbles $25(\mathrm{se}), 3(\mathrm{se})$ and $5(\mathrm{be})$ roll around their longest axis $\left(\mathrm{d}_{\mathrm{a}}\right)$, pebble 6 (bas) rolls around its shortest axis $\left(\mathrm{d}_{\mathrm{c}}\right)$. Their cross-section shape is almost circular (see Fig. 7). Hence the low rolling resistance allows the highest possible velocity. Regarding the velocity trends of these pebbles, it can be concluded that the highest possible velocity has been reached within the flume's length. This velocity trend 1 can be regarded as typical for a consistently inclined slope.

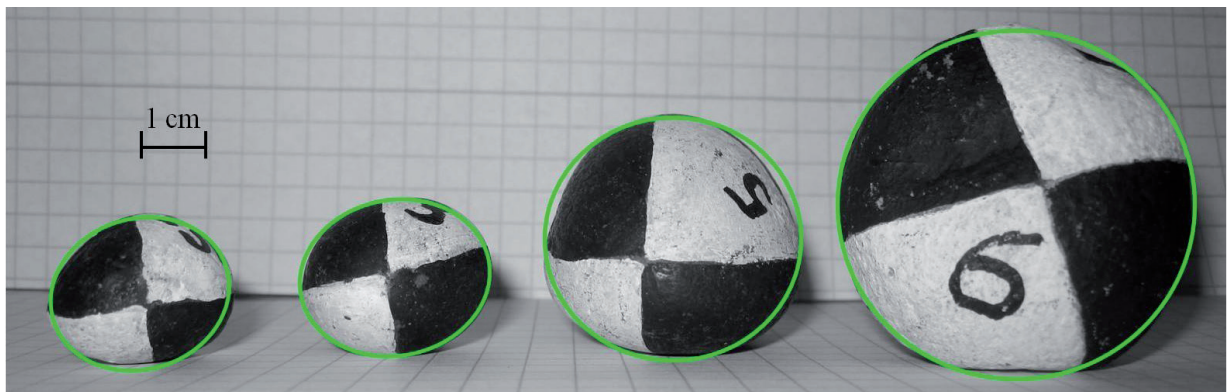

Figure 7. Cross-section shapes of the pebbles 25(se), 3(se), 5(be) and 6(bas). 
Pebbles 7(bf) and 8(bf) also roll around $\mathrm{d}_{\mathrm{a}}$. The cross-section shape in these cases is an ellipse (see Fig. 8). This explains the fluctuations around $0 \mathrm{~m} \mathrm{~s}^{-1}$ at the beginning and the increase of the velocity trend within the further process. The rolling resistance is very high at the beginning and decreases with time and increasing water flow velocity. In these experiments, the maximum possible movement velocity has also been reached but at a later time within the run compared to the smaller pebbles, the big, ellipsoidal pebbles and also pebble 6(bas).

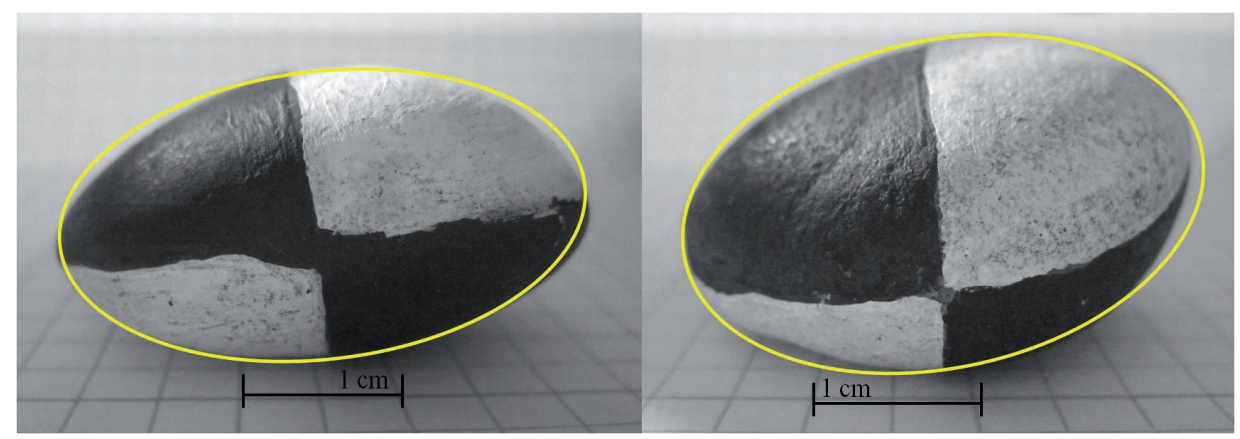

Figure 8. Cross-section shapes of the pebbles 7(bf) and 8(bf).

Also within the $10^{\circ}$ slope experiments the cross-section shapes of the pebbles explain the related velocity trends. These trends differ from the results of the $5^{\circ}$ slope experiments. The experiments reveal a rolling motion around $d_{c}$ for the pebbles 3 (se), 5 (be) and 7(bf). The cross-section shape is elliptic in these experiments. Comparing Fig. 8 and Fig. 9 it is to notice that the ellipses show different circularities. This fact combined with the higher slope of the flume explains the typical velocity trend directly at the beginning and hence the classification as velocity trend 1 . The pebbles reach their final velocity for the given conditions. The pebbles 6(bas) and 8(bf) do not reach their final velocity. The reason is presented in Fig. 10: the cross-section shape is almost perfectly circular. Hence, the rolling resistance is lower than for the other three pebbles. This fact explains the linear increase of the velocity, the overall higher values and the fact, that the highest possible velocity could not be reached during the experiments.

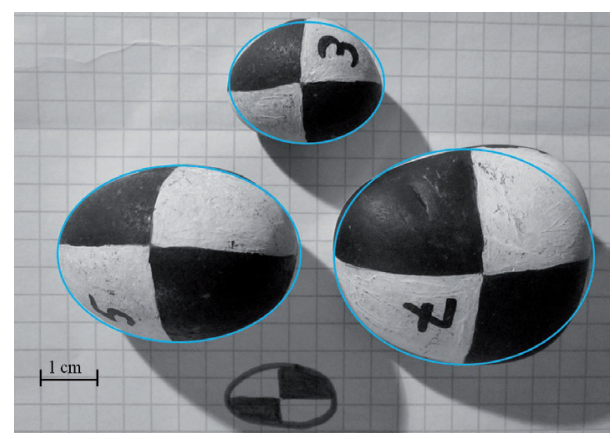

Figure 9. Cross-section shapes of the pebbles 3(se), 5(be) and 7(bf). 


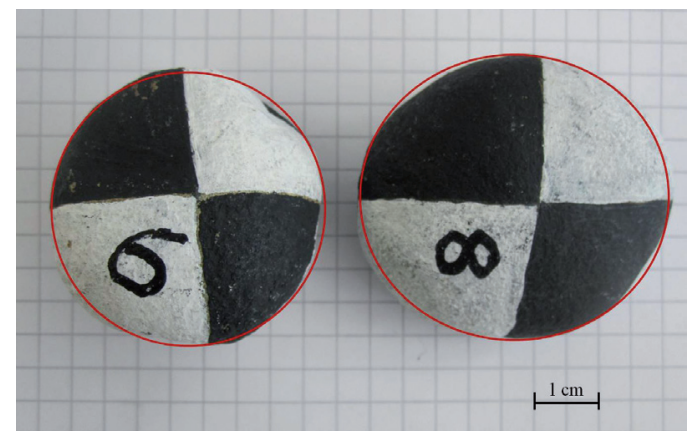

Figure 10. Cross-section shapes of the pebbles 6(bas) and 8(bf).

Velocity trend 5 represents a special feature. The linear increase of the velocity and the overall very low velocity can be explained by the fact that the pebbles 7(bf) and 8(bf) slid within the experiments (see Table 9, orange boxes). The low mean velocity can be explained by the large friction surface of the pebbles and the resulting high moving resistance.

\subsection{Pebble movement patterns}

\subsubsection{Movement patterns for the $5^{\circ}$ slope experiments}

All patterns are shown in tables 6 to 9 using the symbols defined in section 2.3. Before we describe these patterns, we want to present one example in detail for illustration purposes. For it, we use pebble 24(sf) in table 6 . This pebble is the only one showing two different patterns. The second pattern can be read as: Each run starts with the pebble lying in its initial position (first symbol). Afterwards, the pebble remains in this position but pitches: it moves up and down around the axis perpendicular to the flow direction. Then, it rolls around $d_{a}$. The following bracketed pattern occurs only in 2 to 4 runs: the pebble stops and pitches again, followed by rolling around $d_{a}$. Then the pebble changes its rotation axis in all runs and rolls around $d_{c}$, in 2 to 4 runs combined with yawing. The final step is in all runs rolling around $d_{c}$, in 2 to 4 runs combined with saltation.

In the same manner, all movement patterns can be read. Table 6 contains the patterns of the small pebbles for $5^{\circ}$ slope. The repetitive movement patterns of them are obvious: The small, flat pebbles 24 and 2 lie at the beginning, then they roll around $\mathrm{d}_{\mathrm{a}}$, then around $d_{c}$ and finally they show a mixed movement pattern consisting of saltation and rolling around $\mathrm{d}_{\mathrm{c}}$ (Table 6 , orange boxes).

The small ellipsoidal pebbles show a different behavior: Pebbles 25 and 3 lie at the beginning, then they roll around $\mathrm{d}_{\mathrm{a}}$ and rotate simultaneously. Then, they rotate around $\mathrm{d}_{\mathrm{c}}$ and rotate simultaneously and finally they roll around $\mathrm{d}_{\mathrm{a}}$ and saltate simultaneously (Table 6 , red boxes).

The starting orientation explains the movement patterns for ellipsoidal pebbles. Before runoff starts, the pebbles are positioned transverse into the flume $\left(\mathrm{d}_{\mathrm{a}}\right.$ perpendicular to flow direction). As the cross-section shape trough $d_{c}$ (in flow direction) is almost circular, the movement could be easily initiated because of the low rolling resistance in flow direction. 
Table 6. Movement patterns of pebble 24(sf), 25(se),2(sf) and 3(se) during the $5^{\circ}$ experiments.

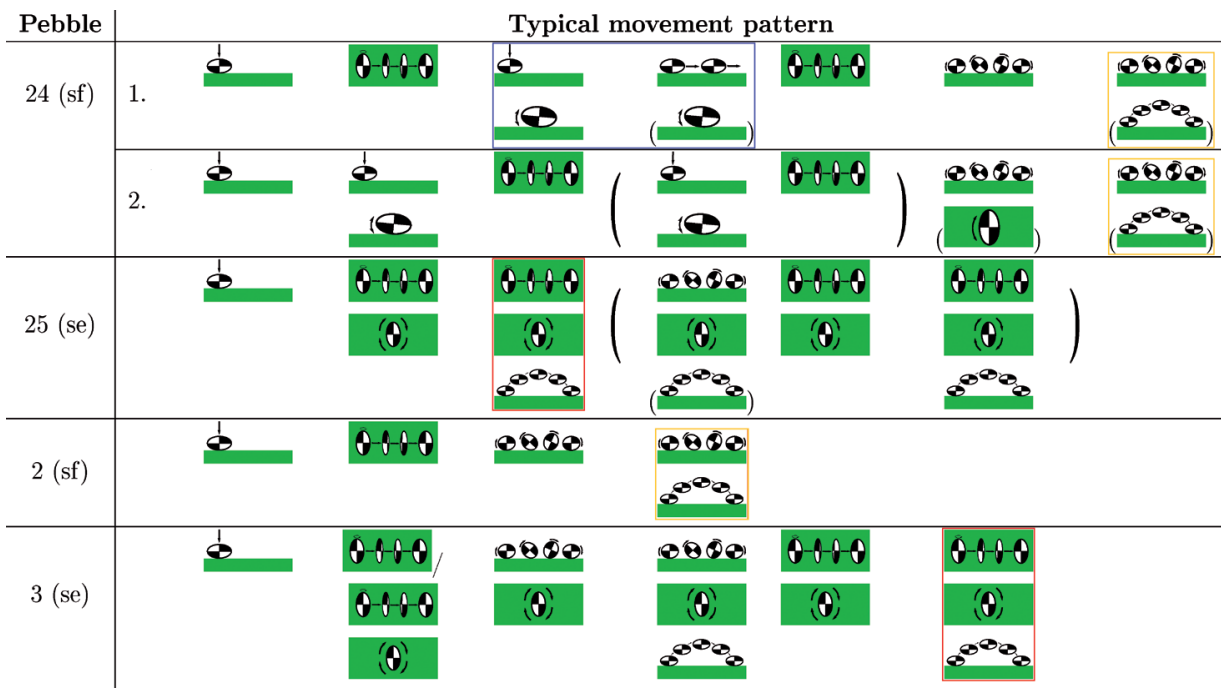

Additionally, we could observe for the given conditions that small, flat pebbles were slid for a certain distance (Table 6, blue box). The blue boxes in table 7 show, that also the big pebbles 7 and 8 , both in orientation FR, were slid in almost all experiments. Pebble 7(bf) slides also in orientation BL in two of four experiments. The big, flat pebbles 7 and 8 show a similar behavior in both orientations at the beginning but at the end, the movement patterns clearly differ. This can be explained by the different circularities.

Table 7. Movement patterns of pebble 7(bf), 5(be), 8(bf) and 6(bas) during the $5^{\circ}$ experiments.

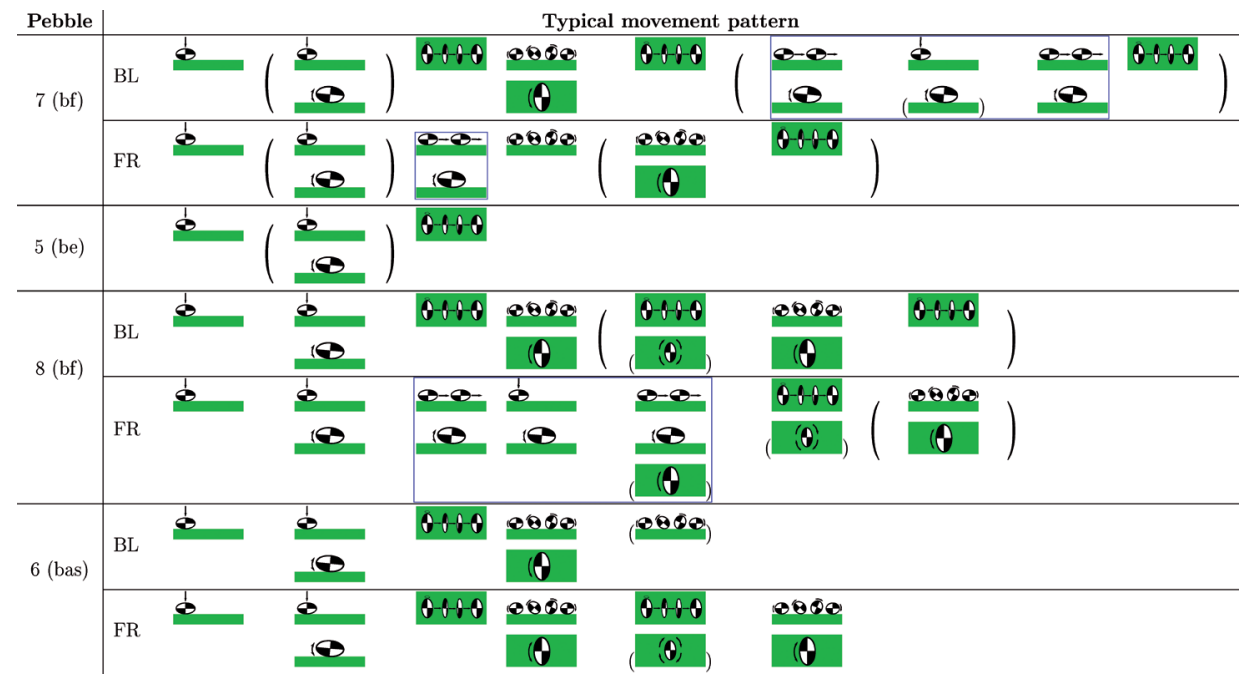


Table 8: Movement patterns of pebble 24(sf), 25(se), 2(sf)

and $3\left(\right.$ se) during the $10^{\circ}$ experiments.

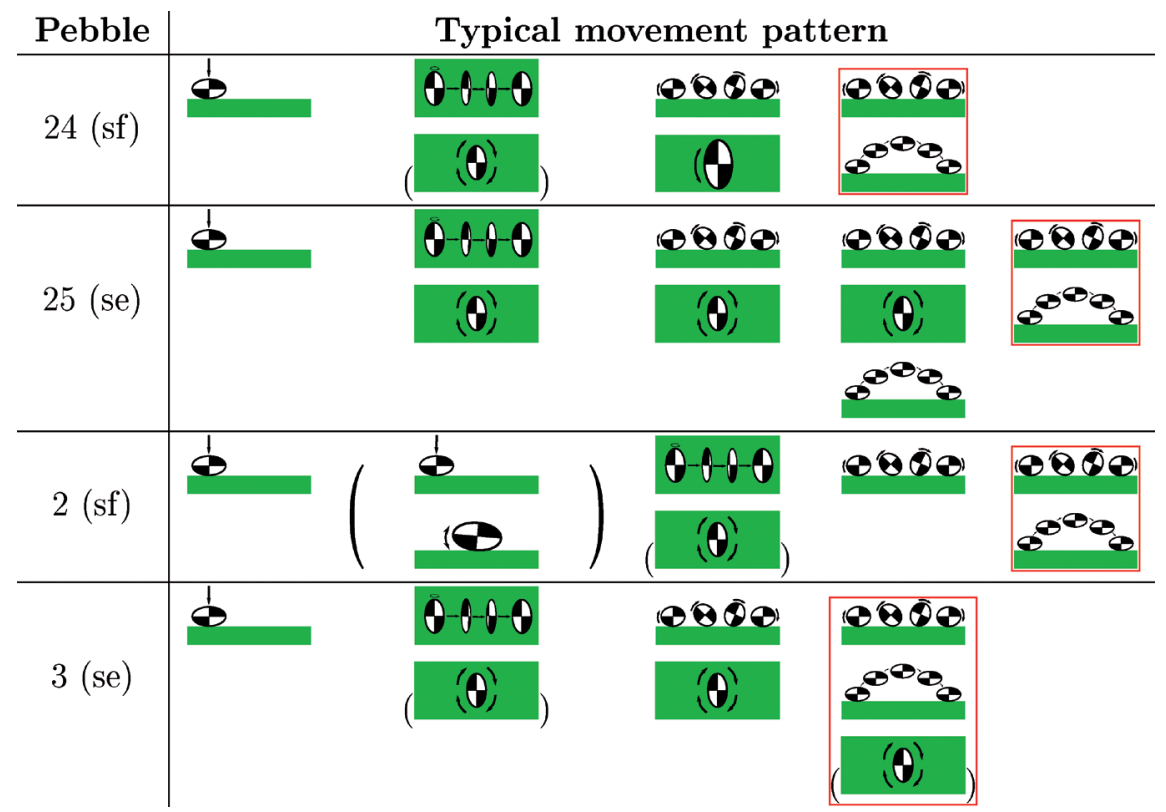

Pebble 5(be) shows a similar behavior as the small, ellipsoidal pebbles but the saltation at the end of the experiment is missing. At the beginning, the pebble lies, then, in two of four experiments, the pebble starts pitching, followed by rolling around $d_{a}$. As in other cases, the cross-section shape is circular. The movement is initiated by impulse repeating from water waves on the pebble due to the low rolling resistance and takes place in two of four experiments.

\subsubsection{Movement patterns for the $10^{\circ}$ slope experiments}

In the $10^{\circ}$ slope experiments we could observe that almost all pebbles roll around $\mathrm{d}_{\mathrm{c}}$ (except for pebbles 7(bf) and 8(bf) in orientation FR, see table 9, orange boxes). This is a major difference compared to the $5^{\circ}$ slope experiments, where the small ellipsoidal pebbles rolled around $\mathrm{d}_{\mathrm{a}}$.

The movement type with the least resistance is rolling. Only the smallest pebble side is oriented in flow direction as the contact surface for the water. In this case, the contact surface is much smaller than in the case where the flat pebble side was oriented in flow direction. In contrast to the $5^{\circ}$ slope experiments this explanation is also valid for the ellipsoidal pebbles in the $10^{\circ}$ slope experiments. The longing for a stable state and the lowest flow resistance control the movement patterns of the pebbles. 
Table 9. Movement patterns of pebble 7(bf), 5(be), 8(bf) and 6(bas) during the $10^{\circ}$ experiments.

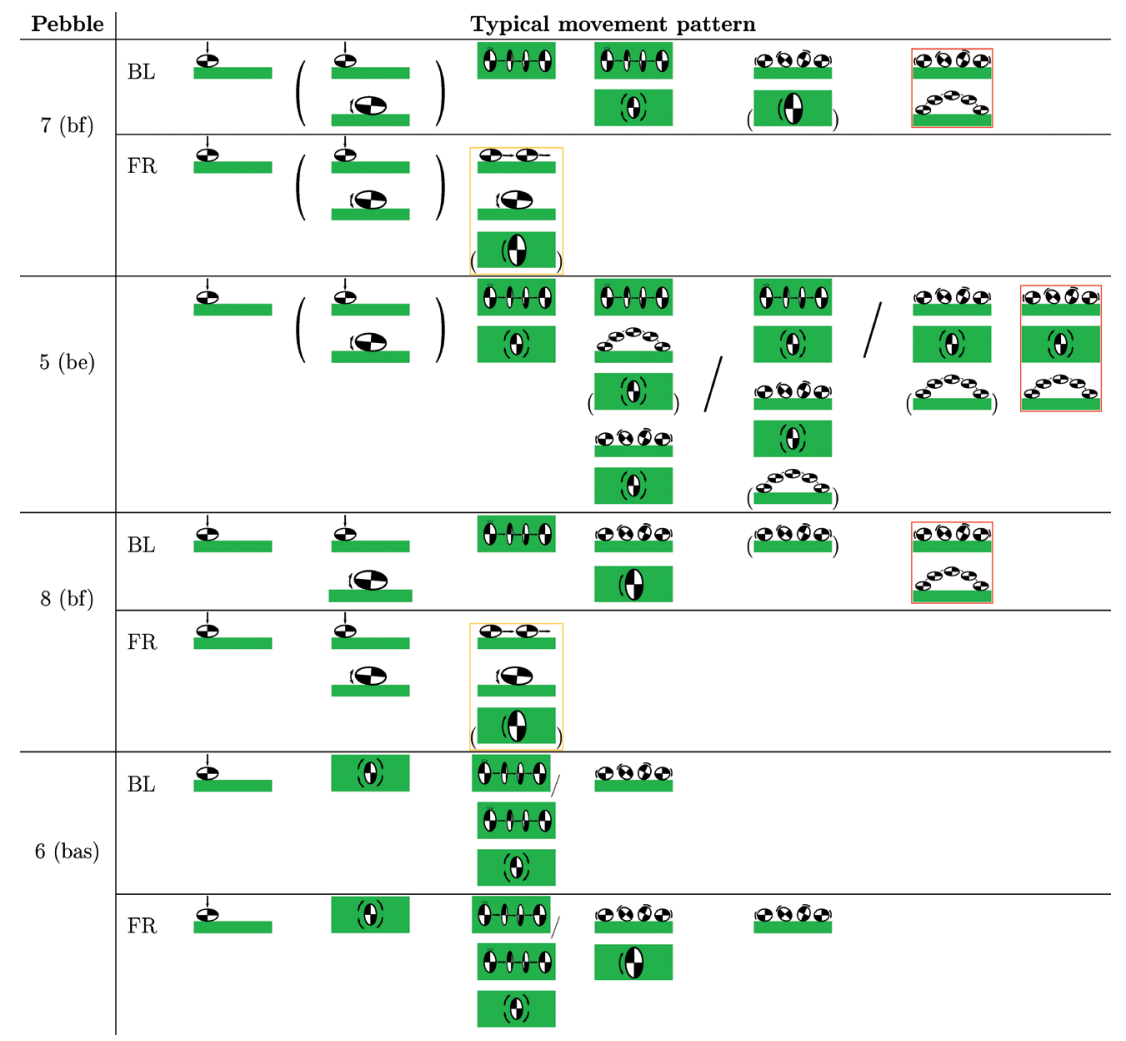

Table 10. Movement patterns of pebble 6 (bas) during the $5^{\circ}$ and the $10^{\circ}$ experiments.

\begin{tabular}{|c|c|c|c|c|c|c|c|}
\hline Pebble & \multicolumn{7}{|c|}{ Typical movement pattern } \\
\hline 6 (bas) & $\mathrm{BL}$ & b & $\frac{1}{10}$ & $0+0$ & 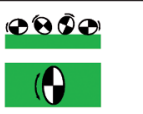 & (1000) & \\
\hline $5^{\circ}$ & FR & b & $e_{10}^{b}$ & $\theta-2-\theta$ & 10 & $\frac{(\theta-6-\theta)}{(\theta)}$ & 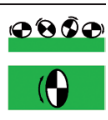 \\
\hline 6 (bas) & & $\frac{1}{e}$ & (0) & $\frac{(\theta-1-\theta)}{(\theta-\theta)}$ & 000 & & \\
\hline $10^{\circ}$ & & 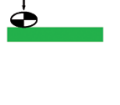 & $(\theta)$ & $\frac{\theta-1-\theta}{\theta-\theta-\theta}$ & $\frac{100}{10}$ & $\theta 00$ & \\
\hline
\end{tabular}


In the case of the almost spherical pebble 6, small deviations from the perfect spherical shape influence the movement patterns; hence the rules for ellipsoidal pebbles are to apply. Fig. 11 presents pebble 6(bas) and its deviations from the perfect spherical shape (red marked), especially in side view.

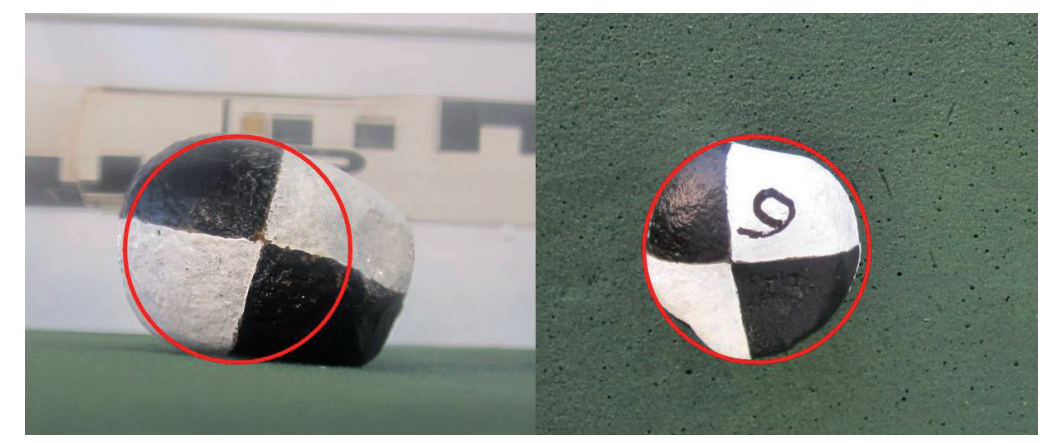

Figure 11. Pebble 6(bas) in side view (left) and top view.

Pebble 6(bas) shows similar movement patterns for both slopes. Only at the end, the pebble yaws in the $10^{\circ}$ slope experiments, this motion is missing in the $5^{\circ}$ slope experiments. This difference can be explained by the almost spherical shape. Hence, the rolling resistance is low and transportation by water is easily possible.

The fact that all pebbles (except for pebble 6 (bas)) saltate in the $10^{\circ}$ slope experiments after the last motion change (red boxes in tables 8 and 9) can also be explained by the shape. Figs. 9 and 10 show an unbalance, meaning a deviation from a perfect circular shape. This unbalance disturbs the rotation around $d_{c}$ and explains the saltation of the pebbles. Pebble 6(bas) is an exception: the cross section trough $\mathrm{d}_{\mathrm{c}}$ is as close to the perfect spherical shape (see Fig. 11, right hand); the deviations are too small to cause saltation. The velocity trend of pebble $8(\mathrm{bf})$ is similar to the velocity trend of pebble 6 and also the cross section through $d_{c}$ is an almost perfect circular shape. But the deviation from the perfect circular shape is sufficient to initiate the saltation.

Within the $10^{\circ}$ slope experiments, the very different movement patterns of pebble 7(bf) and 8(bf) in different orientations are obvious (see table 9, orange boxes). In orientation FR, the big flat pebbles are slid but in orientation BL, they are rolling. Reasons for the large differences in the movement patterns for pebble 7 and pebble 8 in different starting orientations are the shapes of the pebbles and the different slopes with the subsequent different water flow velocities. Fig. 12 shows the different shapes depending on orientation. In orientation BL, the bigger end of the pebble is downslopeoriented, the more pointed end is upslope-oriented. In orientation FR, the bigger end is upslope-, the pointed end downslope-oriented. In the FR orientation, the water is able to lift and push the pebble but because of the downslope oriented pointed end, it is not possible to tilt the pebble and initiate rolling. In the BL orientation, the bigger end is downslope-oriented. In the pointed, upslope-oriented end lifted, the pebble can tilt due to the circular shape of the bigger end and the subsequent lower rolling resistance. In 
this case, rolling can be initiated. It can be concluded that the asymmetrical shape of the pebbles is responsible for the different movement patterns and velocities depending on orientation.

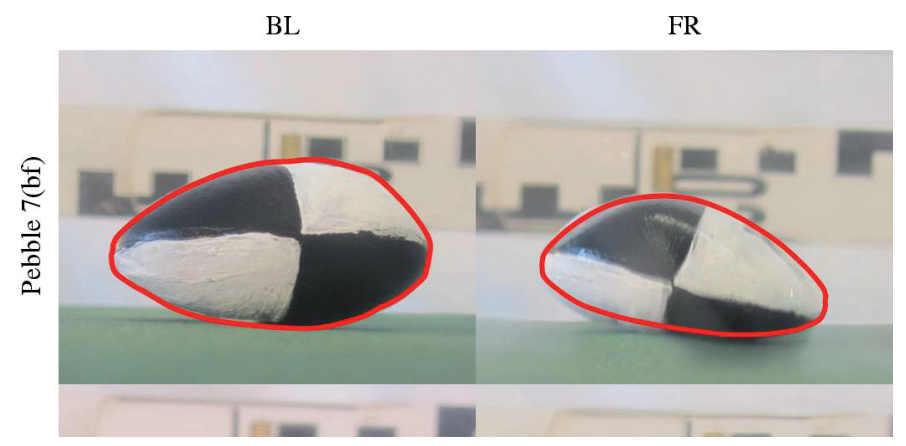

Figure 12. Different shapes in different orientations of pebbles 7 and 8 .

\section{Discussion}

Laboratory studies deliver standardized and controlled conditions to ensure reproducibility. These factors were important for this study - hence we used a box shaped flume with rectangular cross section. The flume bottom was covered by a floral foam plate. The flume and the flume's bottom are not comparable to natural rills developed in natural soils. Hence the transferability on natural systems is only given in a very limited manner but general rules are obvious and can be used as basic for further research.

Comparing the pebble movement patterns for the two different slopes, one main movement pattern within the $5^{\circ}$ slope experiments was the rolling around $d_{a}$, observed for five of eight pebbles; within the $10^{\circ}$ slope experiments, we rather observed a rolling around $d_{c}$. Leser (1977) describes a transverse adjustment of pebbles in lowland river systems and a longitudinal adjustment in intensive fluvial transport situations as in high mountain river systems. If we equate rolling around $\mathrm{d}_{\mathrm{a}}$ with transverse adjustment and rolling around $d_{c}$ with longitudinal adjustment, the results of Leser could also be observed in our experiments on a smaller scale. It is to notice that the ratio between water level and pebble size is much larger in the study of Leser and there are still other differences that forbid a direct comparison, like the missing interaction with other particles in our experiments. But the dynamic of the flowing water in our experiments seems to be sufficient to simulate the differences observed by Leser. Hence, the conclusion of Leser is also valid for our scale.

Bunte and Ergenzinger (1989) used active tracers within their field studies in mountain rivers. Natural pebbles have been equipped with active chips. During the observation time, they delivered information about transport length, transport velocity, starting orientation and orientation after final sedimentation. Additionally, the number of rotations has been counted and hence, in combination with movement velocity, a conclusion about movement patterns was possible. Using this setup, Bunte and 
Ergenzinger (1989) presented a first, rough movement pattern. This movement pattern was characterized by a sliding at the beginning followed by rolling. This movement pattern could be observed in our experiments for the big flat pebbles in the $5^{\circ}$ slope experiments. Because of the different methods, a direct comparison of the movement patterns is only possible in a limited manner.

Cameron (2012) introduced the movement form "vibrating". In this study, we divided "vibrating" into two separate movement forms and used the terms lying and pitching. These forms have not been observed for all pebbles but for the big pebbles at both slopes (except for pebble 6(bas) orientation FR and BL at $10^{\circ}$ slope).

Chatanantavet et al. (2013) analyzed in a laboratory study the movement velocities of saltating pebbles and the concerning saltation heights and lengths. They used differently sized and shaped quartzite pebbles. The pebbles have been dropped into a slightly sloped acrylic glass flume and the saltation under the influence of water has been recorded using a high-speed-camera. Thus, movement velocities depending on pebble size and pebble shape have been determined. Despite the only slightly sloped flume, velocities up to $1.6 \mathrm{~m} \mathrm{~s}^{-1}$ have been reached. In our experiments, we used much steeper slopes but a similar high pebble velocity has not been reached. This can be explained by the different pebble size, different surface roughness of the flume's bottom, different water levels and a different way to insert the pebbles.

Fig. 13 presents the typical trajectory of differently sized saltating particles. This typical trajectory has been determined by Francis (1973) from detailed high-speedphotographs. In our experiments, similar trajectories have been observed on a smaller scale (see Fig. 14).

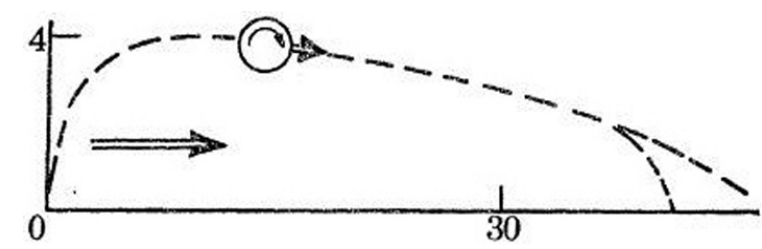

Figure 13. Typical trajectory of saltating particles with different diameters (schema). Source: Francis (1973: 448).

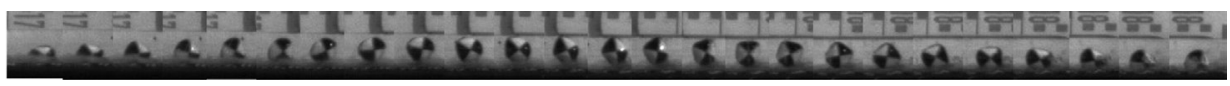

Figure 14. Pebble 24(sf) during a saltation in experiment 6. Extracts of the images 584 to 608.

Poesen (1990) observed the movement of rock fragments up to a diameter of $9 \mathrm{~cm}$. Though our pebbles are slightly smaller, we could also show that pebbles from the middle and coarse gravel class have been moved. The different starting and environmental conditions have no crucial influence on the similarity of the results. 
One possible point of criticism on our setup concerns the used floral foam on the flume's bottom. After each experiment, prints of the pebbles remain in the floral foam. Hence, the starting roughness could not be kept constant in the experiments. The number of the prints increased with the number of experiments, hence the roughness also increased with time (see Fig. 15). To minimize this effect, we started the experiments with the small pebbles. We assume that the small prints did not influence the movement of the following big pebbles decisive. To ensure the reproducibility of the method, the sequence of the pebbles was the same for both slopes. For the $10^{\circ}$ slope experiments, a second, new, print-free floral foam plate has been used.

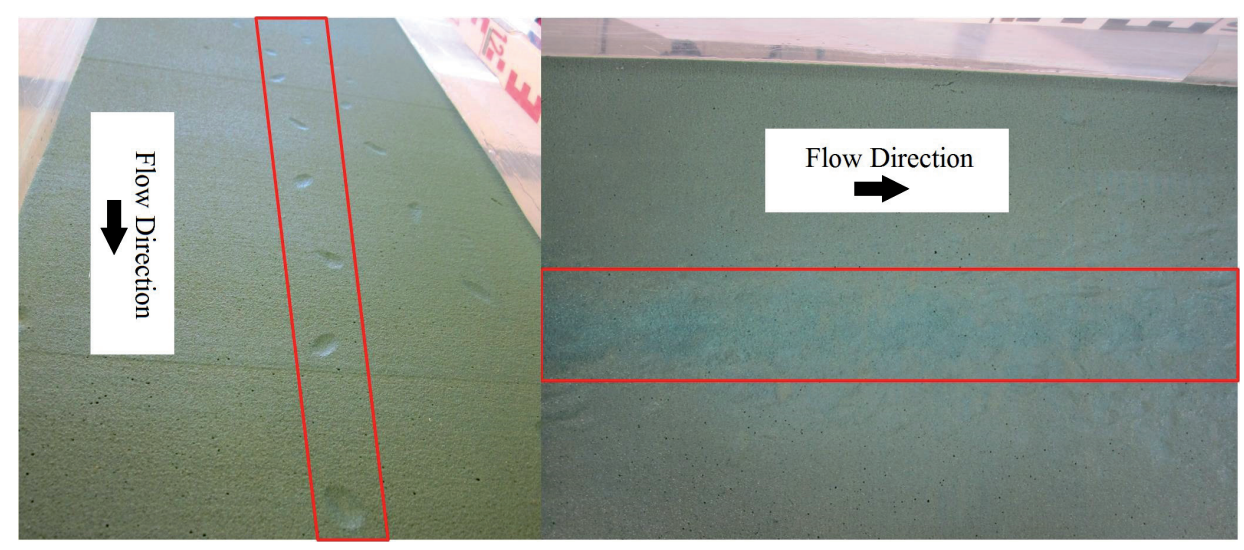

Figure 15. Bottom after two tests (left) and after many tests.

The quality of the high-speed camera greyscale images in combination with the colored structure of the pebbles based on the crash test dummy pattern was sufficient to analyze the movement patterns within our experiments. Images from a high-speed camera able to produce color pictures would improve the capability to differ between water and pebble. This would improve the data quality. But the costs for such a highspeed camera exceeded the financial capabilities of the working group.

This paper only presents an intermediate step of the data analyses. In addition to the presented results, it should be possible to calculate the energy impact of the pebbles on the floral foam surface. The weight of the pebbles is known, the incoming pebble velocity and the leaving velocity of the pebble can be calculated using the timesteps between two images. Hence, the energy of the incoming pebble and of the leaving pebble can be calculated, the difference impacts on the surface.

\section{Conclusions}

Despite several points of criticism, the data delivered by the used methods enable us to derive different movement patterns. Almost each pebble shows an individual movement pattern and in some cases the movement pattern depends clearly from the shape of the pebble. Examples are the almost spherical pebble 6 and the big flat pebbles 
7 and 8. Additionally, a correlation between movement pattern or movement velocity and the different orientations BL and FR could be observed for the flat pebbles with mean diameters between 3 and $4 \mathrm{~cm}$. Furthermore, a correlation between movement pattern and movement velocity concerning transition or change between slow movement forms as lying, sliding or rotating and fast movement forms as rolling and saltating has been observed. Within the analyses of the movement velocities, five different velocity trends could be classified. These trends do not reflect the movement patterns; the velocity trend is mainly controlled by the cross-section shape orthogonal to the rotation axis. The closer this cross-section shape is to a perfect circular shape, the rather the velocity trend shows a linear increase and the higher is the maximum reached velocity of the observed pebble. Additionally, this cross-section shape mainly controls the initiation of saltation within the progress of the experiment, on condition that a smooth flume surface is given. If the cross-section shape differs from a perfect circular shape, saltation can be initiated. A correlation between size and movement velocity could not be observed. The results are reproducible despite some critical points: 1) Surface roughness changed between the experiments, but the influence could be limited by the applied sequence of the pebbles (firstly the small pebbles, later the bigger pebbles) and by the use of a new surface for the experiments with the second slope. 2) The pebbles did not follow the center line of the flume but the lateral movements could not be quantified with the applied setup. 3) The used setup cannot be used under field conditions as optical methods are limited in turbid water-sediment mixtures, in turbulent flows and under the missing option of a side view. Points 2 and 3 will be tackled by the use of a newly developed sensor carrier, the so called "Smartstone". The development of the Smartstone has still begun and will provide data about acceleration, impact forces, orientation and rotations under all possible conditions in the future.

\section{References}

Bunte, K., Ergenzinger, P. 1989. New tracer techniques for particles in gravel bed rivers. Bulletin de la Société Géographique de Liege 25, 85-90.

Bunte, K., Poesen, J. 1993a. Effects of horseshoe vortex erosion on sediment yield from soils covered by rock fragments. Zeitschrift für Geomorphologie 37, 327-335.

Bunte, K., Poesen, J. 1993b. Effects of rock fragment covers on erosion and transport of noncohesive sediment by shallow overland flow. Water resources research 29, 1415-1424.

Cameron, C. 2012. A wireless sensor node for monitoring the effects of fluid flow on riverbed sediment. University of Glasgow. School of Computing Science Level 4 Project, 70 pp.

Canny, J. 1986. A Computational Approach to Edge Detection. IEEE Transactions on Pattern Analysis and Machine Intelligence PAMI-8, 679-698.

Chatanantavet, P.,Whipple, K.X., Adams, M.A., Lamb, M.P. 2013. Experimental study on coarse grain saltation dynamics in bedrock channels. Journal of Geophysical Research: Earth Surface 118, 1161-1176.

Einstein, H. A. 1950. The bed-load function for sediment transportation in open channel flows. 1026. US Department of Agriculture.

Ergenzinger, P., De Jong, C. 2003. Perspectives on bed load measurement. IAHS Publication, 113-125. 
Euler, T., Herget, J. 2012. Controls on local scour and deposition induced by obstacles in fluvial environments. Catena $91,35-46$.

Francis, J. 1973. Experiments on the motion of solitary grains along the bed of a water-stream. Proceedings of the Royal Society of London. A. Mathematical and Physical Sciences 332, 443-471.

Leser, H. 1977. Feld- und Labormethoden der Geomorphologie. Walter de Gruyter, Berlin New York, $464 \mathrm{pp}$.

Meselhe, E., Peeva, T., Muste, M. 2004. Large Scale Particle Image Velocimetry for Low Velocity and Shallow Water Flows. Journal of Hydraulic Engineering, 130, 937-940.

Poesen, J., Torri, D., Bunte, K. 1994. Effects of rock fragments on soil erosion by water at different spatial scales: a review. Catena 23, 141-166.

Poesen, J. 1987. Transport of rock fragments by rill flow - a field study. Catena Supplement 8 , $35-54$.

Poesen, J., Ingelmo-Sanchez, F. 1992. Runoff and sediment yield from topsoils with different porosity as affected by rock fragment cover and position. Catena 19, 451-474.

Poesen, J. 1990. Conditions for the evacuation of rock fragments from cultivated upland areas during rainstorms. Erosion, Transport and Deposition Processes (Proceedings of the Jerusalem Workshop, March-April 1987). IAHS Publication 189, 145-160.

Rieke-Zapp, D., Poesen, J., Nearing, M.A. 2007. Effects of rock fragments incorporated in the soil matrix on concentrated flow hydraulics and erosion. Earth Surface Processes and Landforms 32, 1063-1076.

Rieke-Zapp, D., Beer, A., Turowski, J.M., Campana, L. 2012. In situ measurement of bedrock erosion. International Archives of the Photogrammetry, Remote Sensing and Spatial Information Sciences Volume XXXIX-B5, 429-433.

Sklar, L.S., Dietrich, W.E. 2001. Sediment and rock strength controls on river incision into bedrock. Geology 29, 1087-1090.

Sklar, L.S., Dietrich, W.E. 2004. A mechanistic model for river incision into bedrock by saltating bed load. Water Resources Research 40, W06301, doi:10.1029/2003WR002496.

Steidle, G. 2009. Luftfahrtgeschichte - Flugsteuerung: http://www.luftfahrtarchiv.eu/index.php? option=com_content $\&$ view=article $\&$ id=190:flugsteuerung \&catid=39: grundkenntnisse $\&$ Ite mid=59.

Summerfield, M. A. 1991. Global geomorphology. An introduction to the study of landforms, $537 \mathrm{pp}$.

Wilson, A., Hovius, N., Turowski, J.M. 2013. Upstream-facing convex surfaces: Bedrock bedforms produced by fluvial bedload abrasion. Geomorphology 180, 187-204. 